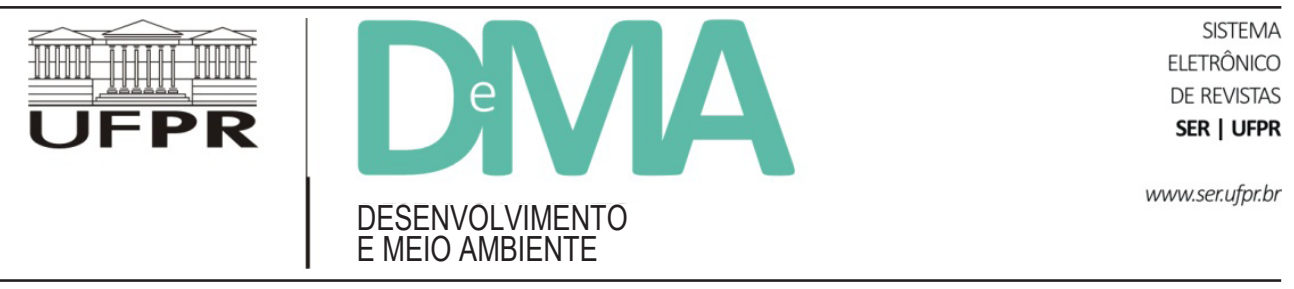

\title{
Percepção de atores sociais de Itajaí (SC) a respeito das variações climáticas, com foco nas inundações
}

\section{Perception of Social Stakeholders of Itajaí (SC) on Climate Variability and Floods}

\author{
Adão de Souza MORAES ${ }^{1 *}$, Rosemeri Carvalho MARENZI ${ }^{1}$, Camila LONGARETE ${ }^{1}$ \\ ${ }^{1}$ Universidade do Vale do Itajaí (UNIVALI), Itajaí, SC, Brasil. \\ *E-mail de contato: adaopsi@yahoo.com.br
}

Artigo recebido em 12 de março de 2015, versão final aceita em 17 de novembro de 2015.

RESUMO: A comunidade científica tem reforçado a convicção de que as variações climáticas têm se intensificado nas últimas décadas, em decorrência das atividades humanas. O Estado de Santa Catarina, nos anos de 2008 e 2011, foi o palco das maiores inundações já registradas na sua história. No presente trabalho, buscou-se analisar a percepção de diferentes atores sociais de Itajaí em relação às variações climáticas e como esse município vem se adaptando após os eventos de inundações. Esta pesquisa tem caráter quanti e qualitativo, com corte transversal, mediante a aplicação de um questionário semiestruturado aos atores sociais representantes de doze instituições governamentais e doze instituições não governamentais. Foi utilizada a técnica da saturação para definição do tamanho da amostra e o método do Discurso do Sujeito Coletivo para análise dos dados. Foi possível constatar que tanto os entrevistados ligados a instituições governamentais como os de instituições não governamentais consideram que as variações climáticas globais estão atuando no município de Itajaí, pois percebem alterações na temperatura, estações do ano mal definidas, além da presença mais constante de inundações. Os dois grupos destacaram que o município tem realizado investimentos de infraestrutura, como a dragagem do rio e desassoreamento. Contudo, atores de instituições não governamentais relataram que falta atitude do poder público municipal. Constatou-se que danos e perdas materiais em Itajaí ampliam o sentimento de impotência da população, mas contribuem para tornar as pessoas afetadas pelas inundações indivíduos mais resilientes, apesar de socialmente pouco organizados, uma vez que os atos coletivos só se mantêm durante os eventos extremos. Programas ou ações educacionais são extremamente importantes, pois podem minimizar os problemas ambientais, especialmente aqueles associados ao assoreamento do rio e impermeabilização dos solos.

Palavras-chave: percepção ambiental; variações climáticas; inundações.

ABSTRACT: The scientific community has reinforced the conviction that climate variability has intensified in recent decades as a result of human activities. The state of Santa Catarina, in recent decades, particularly in 2008 and 2011, was the scene of the largest floods ever recorded in its history. In this study, we sought to analyze the perception 
of different social stakeholders in Itajaí about climate variability and how this municipality has been adapting itself after flood events. This research study has a cross-sectional, quantitative and qualitative character, by administering a semi-structured questionnaire to social stakeholder representatives of twelve governmental institutions and twelve non-governmental institutions. A saturation technique was used to define the samples, as well as the Collective Subject Discourse method for data analysis. It was possible to state that respondents from both governmental institutions and non-governmental institutions consider that global climate variability is acting on the city of Itajaí, as they perceive changes in temperature, poorly-defined seasons, as well as more frequent flooding. The two groups acknowledge that the municipality has invested in infrastructure such as drainage, deepening and dredging of the river. However, non-governmental institutional stakeholders perceive a lack of commitment by the municipal government. The damage and property losses in Itajaí intensify the feelings of powerlessness, but contribute to making those affected by the floods more resilient individuals; however, they remain poorly socially organized, since collective acts are maintained only during extreme events. Educational programs or actions are extremely important, because they can minimize environmental problems, especially those associated with the silting of the river and soil sealing.

Keywords: environmental perception; climate variability; floods.

\section{Introdução}

A comunidade científica vem demonstrando que as variações climáticas têm se intensificado nas últimas décadas, em decorrência das atividades humanas, classificadas como antrópicas. Tais indícios têm sido constatados em diferentes estações meteorológicas em diversas partes do mundo, as quais têm destacado aumento significativo na temperatura global nos últimos anos (Righi \& Robaina, 2010; IPCC, 2014). Para Buckerige (2008), o aumento da temperatura no planeta tende a gerar impactos nas espécies, nos ecossistemas e, lamentavelmente, profundas consequências na biodiversidade, causando grandes episódios de extinção de fauna e flora. Também estudos realizados pela Organização das Nações Unidas (ONU) apontam que milhões de pessoas em todo mundo têm sido vítimas de desastres naturais, incluindo secas devastadoras na China e na África e inundações na Ásia e na África (Marengo, 2008).

O clima tropical propicia desastres naturais na estação chuvosa, especialmente no verão. Contudo, no Brasil as inundações e os deslizamentos têm sido apontados como os desastres naturais mais comuns, que têm se repetido a cada verão, resultando em centenas de mortes e riscos para a saúde humana. Nos últimos anos, o país tem presenciado, com frequência cada vez maior, situações de desastres, tanto naturais como provocados pelos homens e que, na maioria das vezes, produzem elevado número de vítimas e causam grande comoção popular
(Melo \& Santos, 2011). Lamentavelmente, os principais fatores que agravam ou provocam a recorrência de tais acidentes têm sido apontados como fatores antrópicos: falta de planejamento urbano, mau gerenciamento de bacias hidrográficas, aumento da população em centros urbanos, ocupação desordenada e intenso processo de urbanização e industrialização (Kobiyama et al., 2006).

Também para Kobiyama et al. (2006), existe distinção entre situações onde normalmente as águas dos cursos d'água se elevam, principalmente em ocasiões de chuvas, mas não extrapolam o leito do rio, denominadas de enchentes, e as situações onde ocorre o transbordamento das águas para além do leito do rio em direção às áreas próximas a ele, as inundações, além das situações em que a intensidade de chuvas em um determinado local ocasiona inundações bruscas, denominadas de enxurradas.

Santos (2010) define inundação como um processo de extravasamento das águas do canal de drenagem para as áreas marginais (planície de inundação, várzeas ou leito maior do rio) quando a enchente atinge cota acima do nível máximo da calha principal do rio. De acordo com Tucci (2008), as inundações ocorrem de duas maneiras: a) às margens de cursos d'água (ribeirinhas), que são inundações naturais que surgem no leito maior dos rios por causa da variabilidade temporal e espacial da precipitação e do escoamento na bacia hidrográfica 
(causas físicas, naturais); e b) em razão da urbanização, quando as inundações ocorrem na drenagem urbana por causa do efeito da impermeabilização do solo e canalização do escoamento ou obstruções ao escoamento (causas sociais). Em Itajaí, Santa Catarina, observa-se que ocorrem as duas maneiras de inundações.

As inundações são fenômenos que ocorrem com frequência e afetam a vida de milhões de pessoas a cada ano, principalmente nos países em desenvolvimento e em grandes centros urbanos, com tendência de aumento nas próximas décadas. Correspondem a cerca de $60 \%$ dos desastres naturais registrados no país e $70 \%$ na América Latina e Caribe (Freitas \& Ximenes, 2012).

Em Santa Catarina, as inundações têm sido registradas ao longo da sua história. Santos (2010) descreve estudos de Frank \& Pinheiro (2003) que demonstram registros de inundações superiores a dez metros em cidades drenadas pelo Rio Itajaí, desde o ano de 1852. Também Santos et al. (2014) destacam estudos (Frank, 2003; Aumond et al., 2009) que apontam que, desde os primeiros registros até o ano de 2008, Blumenau-SC havia registrado 69 eventos de inundações (Blumenau localiza-se próximo a Itajaí e tem o Itajaí-Açu como principal rio.)

De acordo com Roseguini \& Mendonça (2010), a região de Itajaí sofreu grandes episódios de inundações, afirmando que principalmente nos anos de 1974, 1983, 1984, 1995, 2004 e 2005 a Defesa Civil de Santa Catarina registrou grandes eventos de inundações no Estado. Um dos eventos extremos mais marcantes registrados em SC, segundo Jorge (2009), foi em 1983, com o fenômeno El Niño, quando toda a região do Vale do Rio Itajaí foi seriamente afetada, destacando-se a cidade de Blumenau.

Em relação a um período mais recente, Mezoni (2011) ressalta que, nos anos de 2008 e 2011, o Estado foi o palco das maiores inundações já registradas na sua história. Em novembro de 2008, as chuvas intensas atingiram aproximadamente $700 \mathrm{~mm}$ em um período de tempo muito curto. Centenas de famílias não tiveram tempo para se defender e sofreram inúmeros prejuízos em diferentes aspectos, com deslizamentos e inundações em muitas áreas, obrigando 14 municípios catarinenses a decretar estado de calamidade pública e 63 a decretar situação de emergência (PPRD, 2009). O desastre assumiu elevadas proporções, tendo seus efeitos mais graves concentrados no Vale do Itajaí, principalmente nas regiões do médio vale e da foz do rio Itajaí-Açu, localizada no município de Itajaí. O Centro de Operações de Defesa Civil de Santa Catarina registrou 135 mortes, 78.656 desalojados e desabrigados 1,5 milhão de afetados (PPRD, 2009). Também no segundo semestre de 2011, especificamente em Itajaí, a inundação ocorrida atingiu $60 \%$ da área urbana e $80 \%$ da zona rural do município, maior que em 2001 e levemente menor que em 2008 (Mezoni, 2011).

Diante do histórico de danos físicos e materiais decorrentes, principalmente dos fenômenos de enchentes e inundações em Santa Catarina, especificamente no Vale do Itajaí, constata-se a necessidade de pesquisas que proporcionem análises envolvendo os eventos extremos em níveis local e regional, pois a existência de estudos regionalizados resulta na elaboração de modelos consolidados que possibilitem apontar, por meio de resultados claros, os efeitos dessa mudança em um território específico (PPRD, 2009). Por outro lado, a falta de estudos locais contribui para o aumento do risco, principalmente em grupos populacionais específicos, menos favorecidos, em decorrência das limitações como planejamentos urbanos precários, infraestruturas inadequadas e desigualdades socioeconômicas e, consequentemente, no acesso a bens e serviços. Caso as ações de mitigação e adaptação não sejam desenvolvidas de forma contundente, na sua máxima eficácia, a tendência é que principalmente os países menos desenvolvidos passem a sentir as consequências das variações climáticas de uma forma mais drástica (Marengo, 2008).

No presente trabalho, buscou-se analisar a percepção de diferentes atores sociais de Itajaí em relação às variações climáticas e como esse município vem se adaptando após os eventos de inundações, principalmente as ocorridas em 2008 e 2011. Optou-se por utilizar o termo variações climáticas, embora o Painel Intergovernamental de Mudanças Climáticas (IPCC, 2014) as defina como mudanças no estado do clima que podem ser identificadas por alterações na média e ou na variabilidade das suas propriedades, que persistem durante um longo período de tempo, tipicamente décadas ou mais, e podem ser ocasionadas por processos internos naturais ou forças externas, tais como modulações dos ciclos solares, erupções vulcânicas e por mudanças 
antropogênicas persistentes na composição da atmosfera ou no uso da terra. No entanto, o conceito de "mudanças climáticas" vem sofrendo muitas deturpações, seja pela pressão da mídia, seja pelas ideologias políticas ou subjetividade das pessoas, de modo que o sentido dessa expressão vem assumindo uma conotação ainda muito imprecisa do ponto de vista científico e também muitas vezes negligenciado diante de uma análise mais precisa no que se refere a parâmetros de tempo e espaço. Embora outras terminologias, como variabilidade ou oscilações climáticas, também careçam de maior rigor científico, no entanto, demonstram-se mais flexíveis se comparadas ao imperativo que o termo mudanças climáticas hoje representa (Casagrande et al., 2011).

\section{Metodologia}

\section{1.Área de Estudo}

A cidade de Itajaí está situada no Estado de Santa Catarina, na Mesorregião do Vale do Itajaí, Latitude

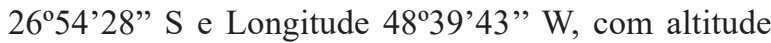
média de $1 \mathrm{~m}$. Possui área de 288,274 km² e faz limite com os municípios de Balneário Camboriú, Camboriú, Brusque, Gaspar, Ilhota e Navegantes (IBGE, 2015). Ao leste limita-se com o Oceano Atlântico, situando-se a foz do rio Itajaí-Açu (Figura 1).
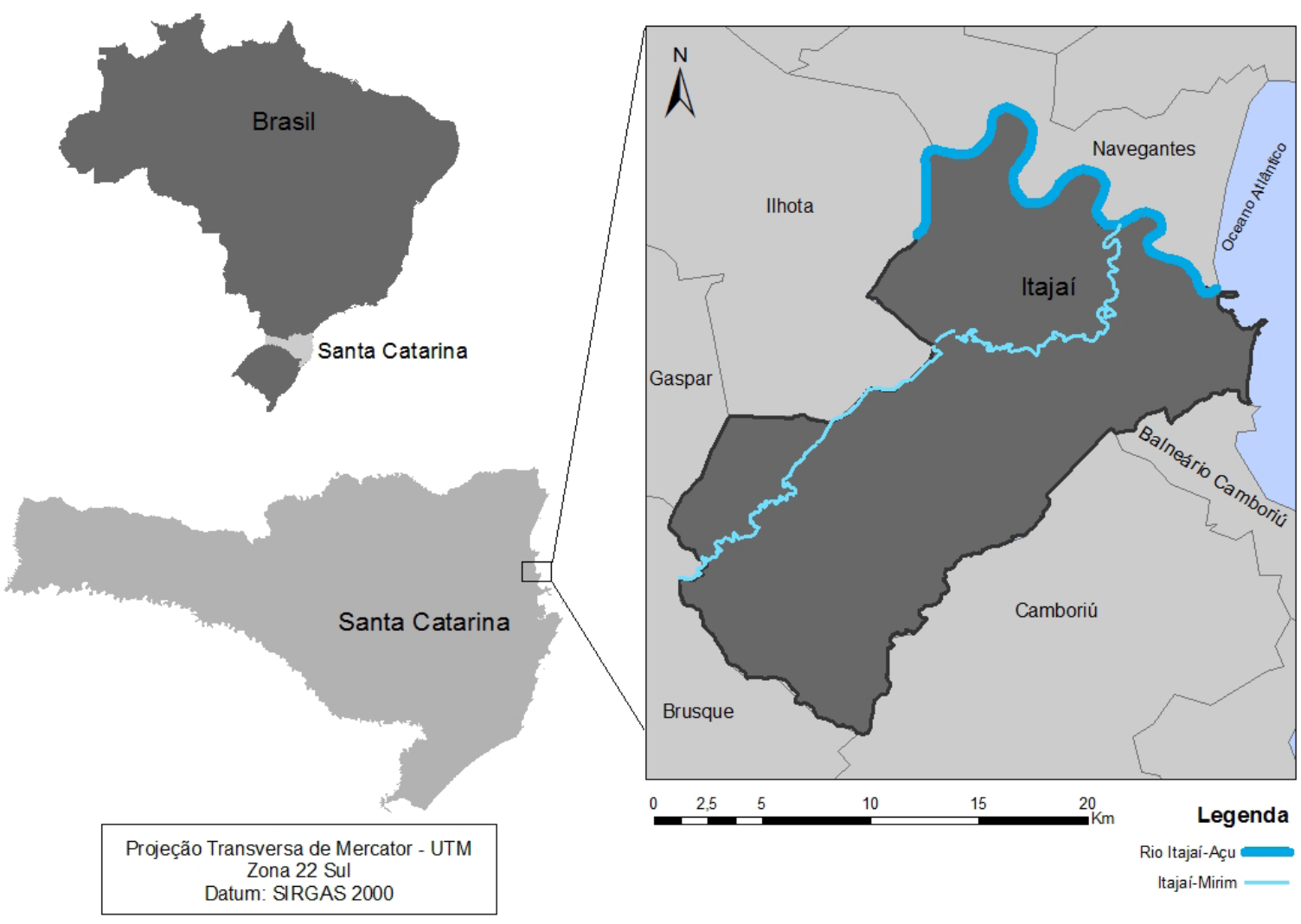

FIGURA 1 - Localização do município de Itajaí, SC, Brasil.

FONTE: Laboratório de Conservação e Gestão Costeira - UNIVALI

414 MORAES, A. de S.; MARENZI, R. C.; LONGARETE, C. Percepção de atores sociais de Itajaí (SC) a respeito das variações climáticas... 
O rio Itajaí-Açu está inserido na Bacia Hidrográfica do Rio Itajaí, composta por uma bacia de drenagem de $15.500 \mathrm{~km}^{2}$. É a principal bacia da Vertente Atlântica do Estado de Santa Catarina, situando-se entre as bacias do Rio Itapocu, ao norte $\left(2.930 \mathrm{~km}^{2}\right)$, e Bacia do Rio Tijucas, ao sul $\left(2.420 \mathrm{~km}^{2}\right)$. Estas três bacias juntas somam mais de $60 \%$ da área da Vertente Atlântica em Santa Catarina. Estão limitadas pela Serra do Mar, ao norte, e pela Serra Geral, a oeste e ao sul do estado. Esta área corresponde a $16,5 \%$ do território catarinense, onde vivem mais de um milhão de habitantes (Santos, 2010).

Na Fachada Atlântica Sul Brasileira, as temperaturas apresentam maiores médias nas planícies, diminuindo com o aumento da altitude e da latitude; a pluviosidade média anual é de 1812,4 mm, sem estação seca, mas períodos de menor precipitação, predominando massa Polar atlântica $(\mathrm{mPa})$, principalmente no inverno, e massa Tropical atlântica (mTa), no verão, assim como também a atuação dos sistemas frontais (Jorge, 2009). O autor destaca a atuação do El Niño e La Niña, ocasionando eventos extremos em diferentes partes da Fachada Atlântica Sul, sendo que as adversidades associadas a estes eventos estão principalmente relacionadas ao aumento do total pluviométrico.

Além de Santa Catarina estar sujeita à ação de eventos extremos, especialmente Itajaí apresenta susceptibilidade natural às inundações decorrente da situação geográfica, por localizar-se na foz do Rio Itajaí recebendo a forçante hídrica de toda bacia hidrográfica à montante, intensificada pelo processo de urbanização na região estuarina. Além disso, a região do Vale do Itajaí está localizada em um vale em formato côncavo em sua maioria, o que a predispõe à ocorrência de enchentes, inundações e deslizamentos (Roseguini \& Mendonça, 2010).

Segundo Polette (2012), em relação à precipitação o município de Itajaí possui boa distribuição de chuvas durante o ano, com uma média de 1.755 milímetros e com médias mensais acima de $80 \mathrm{~mm}$. Também no que se refere à temperatura, o município possui uma média anual de $20,4^{\circ} \mathrm{C}$, com média entre $\left(15,4^{\circ} \mathrm{C}\right)$ e $\left(16,3^{\circ} \mathrm{C}\right)$ nos meses de junho e nos meses considerados mais frios do ano e entre $\left(24,7^{\circ} \mathrm{C}\right)$ e $\left(23^{\circ} \mathrm{C}\right)$ em fevereiro e março, respectivamente, considerados os meses mais quentes do ano (Polette, 2012).

\subsection{Procedimentos de coleta e análise dos dados}

Esta pesquisa é de caráter misto (quanti e qualitativa), corte transversal, com os atores sociais, mediante a aplicação de um questionário semiestruturado. Denominou-se de atores sociais (stakeholders) os entrevistados ligados a instituições públicas, organizações não governamentais (ONG), agrupamentos sociais, pessoas estratégicas da comunidade, ou seja, indivíduos que exerçam algum tipo de liderança na comunidade, "as partes interessadas" (Rejaneda et al., 2011).

No final de cada entrevista, solicitava-se que o entrevistado indicasse o nome de alguém que fizesse parte de alguma instituição que tivesse colaborado, de alguma maneira, com o enfrentamento das últimas inundações. Posteriormente, buscou-se contato com essas pessoas, formando assim uma rede de sujeitos entrevistados. Quanto ao tamanho da amostra, foi utilizada a técnica da saturação, que, segundo Bitsch (2005) e Fontanella et al. (2008), é usada para estabelecer ou fechar o tamanho final de uma amostra em estudo, interrompendo a captação de novos componentes, quando os dados obtidos passam a representar, na opinião do pesquisador, certa redundância ou repetição.

Assim, na presente pesquisa, realizaram-se 24 entrevistas, com 12 sujeitos ligados a instituições governamentais, entre as quais secretarias do poder público municipal, câmara de vereadores e defesa civil, e 12 pertencentes a instituições não governamentais, como Universidade, Porto de Itajaí, imprensa, empresas do setor portuário, imobiliário, comercial e agropecuário, cooperativas, construção civil, Observatório Social de Itajaí e União das Associações de Moradores de Itajaí. As entrevistas foram realizadas na cidade de Itajaí, no primeiro semestre de 2014.

A pesquisa teve a aprovação do Comitê de Ética da Universidade do Vale do Itajaí (UNIVALI). Utilizou-se o Termo de Consentimento Livre e Esclarecido (TCLE), quando os sujeitos, após serem informados sobre a finalidade e a natureza da pesquisa, puderam optar, de livre e espontânea vontade, em participar deste estudo, considerando a sua disponibilidade de tempo e motivações pessoais.

As perguntas foram agrupadas em itens: percepção das variações climáticas, vulnerabilidade às mesmas, da- 
nos referentes às inundações, resiliência após os eventos de inundações e adaptação e investimentos políticos e educacionais.

Para a análise dos dados, optou-se em trabalhar com a metodologia do Discurso do Sujeito Coletivo, desenvolvida por Lefevre \& Lefevre $(2003$; 2006) e Figueiredo et al. (2013), que constitui-se em uma técnica de tabulação e organização de dados qualitativos que permite que se conheça os pensamentos, as representações, as crenças e os valores de uma coletividade sobre um determinado assunto, utilizando-se de métodos científicos. Para Lefevre \& Lefevre (2006), esta técnica tem demonstrado eficácia para o processamento e expressão das opiniões coletivas, porque permite descrever em detalhes a representação subjetiva do cotidiano das relações dos sujeitos pesquisados. As opiniões foram registradas de forma individual e os dados de acordo com a sua frequência, observando-se a ideia central de cada opinião e as agrupando segundo as ideias centrais (IC), montando assim, por meio das falas individuais, uma fala coletiva denominada de discurso do sujeito coletivo (DSC) (Lefevre \& Lefevre, 2006; Figueiredo, 2013).

Os dados obtidos foram sistematizados em formas de tabelas que representavam as falas (discursos) dos sujeitos, de acordo com as ideias centrais (IC). Apesar de cada grupo possuir doze sujeitos, em algumas perguntas obteve-se um número maior de respostas, pois cada respondente emitiu mais de uma opinião sobre aquela questão.

\section{Resultados e discussão}

Quando questionamos os representantes das lideranças governamentais e não governamentais sobre se percebem as variações climáticas em Itajaí, verificou-se em seus discursos, de maneira geral, que constatam algum tipo de modificação no clima, seja devido a chuvas repentinas, mal distribuídas ou muito intensas, ou estações do ano mal definidas, que comprovam a realidade das alterações climáticas (Tabela 1).
TABELA 1 - Percepção dos atores sociais sobre como as variações climáticas globais estão atuando no município de Itajaí (SC).

\begin{tabular}{|c|c|c|}
\hline & $\begin{array}{c}\text { Respostas dos Atores de Instituições } \\
\text { Governamentais }\end{array}$ & $\mathbf{N}^{*}$ \\
\hline A & $\begin{array}{l}\text { Alterações na temperatura, estações do ano mal } \\
\text { definidas, enchentes. }\end{array}$ & 16 \\
\hline B & Problemas na saúde: ocorrência de bactérias, vírus. & 1 \\
\hline \multirow[t]{2}{*}{$\mathrm{C}$} & $\begin{array}{l}\text { Mudanças nas floradas das plantas, perdas na } \\
\text { agricultura. }\end{array}$ & 1 \\
\hline & $\begin{array}{c}\text { Respostas dos Atores de Instituições Não } \\
\text { Governamentais }\end{array}$ & $\mathbf{N}$ \\
\hline A & $\begin{array}{l}\text { Alterações na temperatura, estações do ano mal } \\
\text { definidas, enchentes. }\end{array}$ & 10 \\
\hline B & $\begin{array}{l}\text { Altas temperaturas, poluição; as pessoas estão } \\
\text { buscando mais o verde para morar porque se sentem } \\
\text { sufocadas com as mudanças do clima. }\end{array}$ & 1 \\
\hline $\mathrm{C}$ & $\begin{array}{l}\text { As pessoas fazem parte do universo e são parte de } \\
\text { um ecossistema único. }\end{array}$ & 1 \\
\hline
\end{tabular}

Observa-se que o termo inundação não foi utilizado nas respostas, mas apenas enchente, pois, mesmo que tecnicamente haja distinção entre estes termos, possivelmente há certa confusão pelos entrevistados, já que em Itajaí os eventos extremos transformam as enchentes em inundações. De qualquer forma, a problemática das inundações surge como consequência do aumento da intensidade das chuvas, apontada pelos entrevistados. A maioria deles (16 e 10 respostas, respectivamente) foi categórica em afirmar que as alterações na temperatura, nas estações do ano e nos ciclos de chuvas são bastante evidentes nos últimos anos. Este fato vai de encontro aos estudos que apontam que nos últimos anos as alterações climáticas vêm apresentando significativo agravamento (Buckerige, 2008; Marengo, 2008; Righi \& Robaina, 2010), sejam decorrentes das alterações climáticas globais, naturais, antrópicas ou de um conjunto de todos esses fatores, assim como os alertas para os riscos e consequências das inundações em decorrência da existência de eventos extremos, causados pelas alterações climáticas (IPCC, 2014).

Segundo Fogaça \& Limberber (2014), ao destacar estudos de Okamoto (2002), primeiramente nós adquirimos a sensação do meio, mas sem ter consciência disso, mas depois que a mente seleciona os estímulos que são emitidos, ocorre a percepção, levando-se em considera- 
ção aspectos de interesse ou de atenção. Só então ocorre a consciência (pensamento, sentimento), que resulta em uma resposta caracterizada por um comportamento. Além disso, Sartori (2010) e Wollmann, destacando estudos de Tuan (1980), afirmam que "após perceber, sentir e interpretar um fenômeno natural, o homem passa a estabelecer regras e relações entre suas percepções e a desenvolver a cognição, passando não mais a só perceber o fenômeno, mas também a conhecê-lo, ou seja, o estado de percepção ambiental passa para o de cognição ambiental" (p. 108), o que faz com que cada evento seja captado e interpretado de forma muito peculiar para cada indivíduo.

$\mathrm{Na}$ Tabela 2, estão sistematizadas as respostas que se referem às questões que tratam das iniciativas do poder público municipal quanto à redução de vulnerabilidade às variações climáticas.

TABELA 2 - Percepção dos atores sociais sobre as iniciativas que o poder público municipal vem adotando para reduzir a vulnerabilidade frente às variações climáticas em Itajaí (SC).

\begin{tabular}{|c|c|c|}
\hline & Governamentais & $\mathrm{N}$ \\
\hline A & Estruturação da defesa civil. & 09 \\
\hline B & $\begin{array}{l}\text { Aprofundamento do leito do rio, drenagem, } \\
\text { desassoreamento. }\end{array}$ & 06 \\
\hline $\mathrm{C}$ & $\begin{array}{l}\text { Adoção de medidas de controle das cheias, reforço } \\
\text { das barragens. }\end{array}$ & 01 \\
\hline $\mathrm{D}$ & Fiscalização, licenciamento. & 01 \\
\hline $\mathrm{E}$ & Poucas, não existem árvores às margens dos rios. & 01 \\
\hline $\mathrm{F}$ & $\begin{array}{l}\text { Nenhuma suficiente; apenas há projetos em } \\
\text { estudos. }\end{array}$ & 01 \\
\hline \multirow[t]{2}{*}{ G } & Desconhecimento. & 01 \\
\hline & $\begin{array}{c}\text { Respostas dos Atores de Instituições Não } \\
\text { Governamentais }\end{array}$ & $\mathbf{N}$ \\
\hline A & Estruturação da defesa civil. & 06 \\
\hline B & Investimento em saneamento, novas galerias. & 06 \\
\hline $\mathrm{C}$ & Falta de atitude política. & 06 \\
\hline $\mathrm{D}$ & Coleta seletiva de lixo. & 01 \\
\hline $\mathrm{E}$ & Evitando novas ocupações em áreas de risco. & 01 \\
\hline
\end{tabular}

De maneira gradual, observa-se que, além de o município ter investido no aparelhamento da defesa civil, também investiu em obras de infraestrutura, principalmente em macrodrenagem, dragagem dos rios e rede de esgoto. Importante ressaltar que tais ações tiveram um incremento maior a partir das inundações de 2008.
Segundo relatório da Defesa Civil de Itajaí, a partir do início de 2009, visando se adequar às regulamentações previstas pelo art. 19 da Lei Complementar $n^{\circ} 151$, de 12 de março de 2009, do Poder Executivo de Itajaí, houve possibilidade de estruturação organizacional dessa instituição, com aquisição do quadro de pessoal permanente e capacitado, jornada de trabalho, aquisição de veículos e sede própria, o que proporcionou maiores condições de execução de atividades como: "mapeamento de áreas de risco de inundações, encostas e instalação de equipamentos de monitoramento dos rios, telemetria".

Para Melo \& Santos (2011), a Defesa Civil é um serviço governamental, que desenvolve um conjunto de ações de prevenção, socorro, assistenciais e reconstrutivas, destinadas a evitar ou minimizar os desastres, preservar a integridade física e moral da população e restabelecer a normalidade social. Neste sentido, compete ao poder executivo municipal, por meio da defesa civil, oferecer condições para que a comunidade possa se prevenir e desenvolver respostas adequadas frente a um desastre, mediante ações de prevenção, realizadas no período chamado de "normalidade", visando reduzir a incidência de desastres ou minimizar os danos e prejuízos decorrentes destes. Reichert (2011) defende que o enfrentamento das emergências e dos desastres está diretamente ligado à participação e à preparação da comunidade, por meio da organização da sociedade civil.

Outra ação que o município desenvolveu, na percepção das duas categorias de sujeitos pesquisados, foram as melhorias da infraestrutura, mediante ações de drenagem e macrodrenagem $(30 \%$ das respostas em cada grupo). Segundo Silveira (2002), denomina-se microdrenagem o processo de coleta das águas superficiais ou subterrâneas, através de pequenas e médias galerias, enquanto que a macrodrenagem refere-se, além das galerias de grande porte, também aos corpos receptores, tais como canais e rios canalizados. Para Tucci (2005), a ampliação do sistema de drenagem, principalmente diante do avanço do processo de urbanização, se faz extremamente necessária.

Além das doenças infectocontagiosas, geralmente os alagamentos provocados pelas inundações também resultam em centenas de famílias desabrigadas, o que provoca uma série de alterações na rotina das famílias e da dinâmica social das populações atingidas durante o 
período de reconstrução (limpezas, reparos, acionamento de seguros, indenizações ou assistência social) ou nos períodos em que as famílias ficam alojadas em abrigos improvisados, principalmente por prefeituras, o que lhes gera um alto índice de estresse, conflitos sociais, aumento de uso de substâncias psicoativas, violência, entre uma série de outros problemas (Freitas \& Ximenes, 2012). Nesse sentido, destaca-se a importância de maior atenção à saúde mental de pessoas atingidas por desastres (Gomes \& Cavalcante, 2012).

$\mathrm{Na}$ Tabela 3, os entrevistados puderam sugerir ações que o município pode desenvolver para reduzir os impactos das ações humanas que intensificam as alterações climáticas.

TABELA 3 - Percepção dos atores sociais sobre as ações que podem ser desenvolvidas no município de Itajaí (SC) para redução dos impactos antrópicos sobre o clima.

\begin{tabular}{|c|c|c|}
\hline \multicolumn{3}{|c|}{ Governamentais } \\
\hline A & Maior fiscalização. & 04 \\
\hline B & Educação, conscientização. & 04 \\
\hline $\mathrm{C}$ & $\begin{array}{l}\text { Programa municipal que incentive o plantio de } \\
\text { mais árvores. }\end{array}$ & 02 \\
\hline $\mathrm{D}$ & Mudança na concepção dos gestores públicos. & 02 \\
\hline $\mathrm{E}$ & Regulamentação dos aterros em Itajaí. & 02 \\
\hline $\mathrm{F}$ & Controle na emissão de poluentes. & 01 \\
\hline G & Racionalização do uso de água. & 01 \\
\hline $\mathrm{H}$ & Ruas mais permeáveis. & 01 \\
\hline I & Implantação de unidades de conservação. & 01 \\
\hline $\mathrm{J}$ & $\begin{array}{l}\text { Maior articulação das diferentes secretarias } \\
\text { municipais. }\end{array}$ & 01 \\
\hline & $\begin{array}{c}\text { Respostas dos Atores de Instituições Não } \\
\text { Governamentais }\end{array}$ & $\mathbf{N}$ \\
\hline A & Educação ambiental. & 09 \\
\hline B & Maior fiscalização. & 06 \\
\hline $\mathrm{C}$ & Maior rigor no plano diretor da cidade. & 03 \\
\hline $\mathrm{D}$ & Desassoreamento dos rios. & 03 \\
\hline $\mathrm{E}$ & Incentivar mais o plantio de árvores. & 03 \\
\hline $\mathrm{F}$ & Tratamento de esgoto. & 01 \\
\hline G & Controle das inundações das regiões ribeirinhas. & 01 \\
\hline $\mathrm{J}$ & Diminuir o concreto e o asfalto. & 01 \\
\hline K & Mais ações da Fundação do Meio Ambiente. & 01 \\
\hline $\mathrm{L}$ & Incentivo para as cooperativas. & 01 \\
\hline M & Diminuir o reflexo do calor - mais cor branca. & 01 \\
\hline
\end{tabular}

Nota-se que as duas categorias pesquisadas apontam uma diversidade de ações que, se somadas, podem minimizar os efeitos sobre o clima. Os dois discursos que mais predominam em ambos os grupos referem-se à importância da educação ambiental e da fiscalização, além de uma série de outras recomendações, principalmente relacionadas à importância do planejamento.

Ações de planejamento, fiscalização e até mesmo de educação ambiental estão relacionadas à importância da governança. De acordo com Brasil (2013), define-se governança como um conjunto de mecanismos de liderança, estratégia e controle postos em prática para avaliar, direcionar e monitorar a atuação da gestão, com vistas à condução de políticas públicas e à prestação de serviços de interesse da sociedade. Nesse sentido, Martins (2010) destaca que os governos locais são fundamentais para implementar políticas públicas relativas às variações climáticas, pelo fato de eles estarem próximos de onde os impactos dessas mudanças tendem a ocorrer e por terem o potencial de empreender ações, tanto de mitigação como de adaptação.

A Tabela 4 apresenta a percepção dos entrevistados a respeito das políticas públicas que Itajaí desenvolve.

TABELA 4 - Percepção dos atores sociais sobre as políticas públicas que o poder público municipal vem adotando frente à possibilidade de novas inundações em Itajaí (SC).

\begin{tabular}{llc}
\hline & Respostas dos Atores de Instituições Governamentais & N \\
\hline A & Fortalecimento da defesa civil, aquisição de \\
& equipamentos. & 11 \\
B & Drenagem, galerias. & 04 \\
C & Insistência junto a órgãos estaduais e federais & \\
& solicitando grandes obras. & 04 \\
D & Orientação ao cidadão. & 01 \\
E & Maior controle no uso e ocupação dos solos. & 01 \\
F & Obras de contenção para proteger o leito do rio & 01 \\
J & Nenhuma. & 01 \\
\hline & $\quad$ Respostas dos Atores de Instituições Não & N \\
& $\quad$ Governamentais & 07 \\
\hline A & Aparelhamento, implementação da defesa civil \\
B & Aumento das galerias, planos de saneamento, melhorias & \\
& no leito do rio. & 03 \\
C Nenhum. & 02 \\
D & Controle mais rígido das construções em áreas de risco. & 01 \\
E & Projetos de contenção das cheias. & 01 \\
F & Prevenção das encostas. & 01 \\
G Retirada de casas em áreas de risco. & 01 \\
H & Existem muitos projetos e pouca ação. & 01 \\
\hline
\end{tabular}


Observa-se que a percepção dos dois grupos referente às políticas públicas adotadas no município para reduzir as inundações é semelhante ao conjunto de ações citadas para reduzir a vulnerabilidade de Itajaí frente às variações climáticas (Tabela 2), especialmente quanto a investir na defesa civil e na drenagem da cidade. Parece que os atores confundem políticas públicas com as ações decorrentes das mesmas.

Para Tuan (1980), a conduta humana está pautada na sua percepção, sendo que a mesma é a tomada de consciência do ambiente pelo homem, o ato de perceber o lugar em que ele está inserido, aprendendo a proteger e a cuidar do mesmo. Portanto, é possível considerar que o fato de alguns representantes nos dois grupos apontarem que nenhuma política pública vem sendo adotada em Itajaí pode demonstrar certo grau de exigência, ligado ao despertar de uma percepção ambiental crítica. Nesse sentido, Kuhnen (2009) destaca a importância de se levar em conta a percepção e o envolvimento da população junto às ações de prevenção e mitigação, onde as ações desenvolvidas devem levar em consideração diferentes contextos: social, político, econômico, cultural e institucional.

A Tabela 5 apresenta a percepção dos entrevistados a respeito dos danos que a população de Itajaí sofreu, principalmente nas últimas inundações de 2008 e 2011.

Observa-se que as lembranças da inundação em Itajaí estão muito presentes na memória da população, de modo geral, inclusive das lideranças entrevistadas, parte das quais foi diretamente afetada. Pode-se dizer que os danos sofridos mais relatados referem-se aos pertences domésticos, utensílios em geral. Em algumas situações, a valorização imobiliária do bairro ficou comprometida. No entanto, também se evidenciam os abalos psicológicos e sociais que marcaram a vida das pessoas.

De acordo com Sá et al. (2008), em uma situação de desastre, por conta da imprevisibilidade, da ameaça, do dano ou da perda, são produzidas emoções muito intensas em todas as pessoas envolvidas nesse processo. A familiaridade com uma catástrofe, seja vivenciando-a direta ou indiretamente, seja acompanhando pela mídia, provoca nocivas percepções psicológicas nas pessoas, como a ideia de que elas não são responsáveis pelos seus próprios destinos e que tudo o que constroem pode ser destruído por acontecimentos que fogem de seus
TABELA 5 - Percepção dos atores sociais sobre os principais danos sofridos pela população frente às inundações em Itajaí (SC).

\begin{tabular}{|c|c|c|}
\hline & $\begin{array}{c}\text { Respostas dos Atores de Instituições } \\
\text { Governamentais }\end{array}$ & $\mathbf{N}$ \\
\hline A & Perdas materiais, móveis, roupas, alimentos. & 09 \\
\hline B & Traumas emocionais, abalos psicológicos. & 06 \\
\hline $\mathrm{C}$ & Perdas imobiliárias, desvalorização nos imóveis. & 06 \\
\hline $\mathrm{D}$ & $\begin{array}{l}\text { Danos à saúde, risco de leptospirose, perda da } \\
\text { qualidade da água. }\end{array}$ & 03 \\
\hline $\mathrm{E}$ & $\begin{array}{l}\text { Perdas afetivas, perdas do que as pessoas levaram a } \\
\text { vida toda para construir. }\end{array}$ & 02 \\
\hline $\mathrm{F}$ & $\begin{array}{l}\text { Necessidade de uso de abrigos por longos períodos, } \\
\text { bem-estar reduzido. }\end{array}$ & 02 \\
\hline G & Perdas de vidas humanas. & 02 \\
\hline $\mathrm{H}$ & $\begin{array}{l}\text { Problemas de segurança, saques, roubos, invasão de } \\
\text { domicílios. }\end{array}$ & 02 \\
\hline I & Perda da relação com o rio. & 01 \\
\hline $\mathrm{J}$ & Perdas morais, perda financeira. & 01 \\
\hline K & Cidade não tão qualificada para se morar. & 01 \\
\hline $\mathrm{L}$ & $\begin{array}{l}\text { Perda da identidade geográfica, quando têm que sair de } \\
\text { onde moram. }\end{array}$ & 01 \\
\hline \multirow[t]{2}{*}{$\mathrm{N}$} & Bueiros entupidos. & 01 \\
\hline & $\begin{array}{c}\text { Respostas dos Atores de Instituições Não } \\
\text { Governamentais }\end{array}$ & $\mathbf{N}$ \\
\hline A & Perdas materiais, utensílios domésticos. & 12 \\
\hline B & $\begin{array}{l}\text { Abalos psicológicos. Desorganização na vida das } \\
\text { pessoas. }\end{array}$ & 07 \\
\hline $\mathrm{C}$ & $\begin{array}{l}\text { Impacto negativo nas empresas, comércio, atividade } \\
\text { portuária. }\end{array}$ & 07 \\
\hline $\mathrm{D}$ & Perdas imobiliárias. & 04 \\
\hline $\mathrm{E}$ & Alteração no ano escolar. & 01 \\
\hline $\mathrm{F}$ & $\begin{array}{l}\text { Alterações nos instintos das pessoas: compaixão, } \\
\text { competição. }\end{array}$ & 01 \\
\hline G & Aumento no preço dos alimentos. & 01 \\
\hline $\mathrm{H}$ & Perdas de bens culturais. & 01 \\
\hline I & Mortalidade de animais. & 01 \\
\hline $\mathrm{J}$ & $\begin{array}{l}\text { Prejuízos à saúde: risco de leptospirose, aumento de } \\
\text { animais peçonhentos. }\end{array}$ & 01 \\
\hline K & Perda de vidas. & 01 \\
\hline
\end{tabular}

controles (Steiner et al., 2013). Um evento extremo constitui-se em estressor natural e social capaz de despertar a sensação de impotência humana. A resposta para esses sentimentos poderá ser de uma completa descrença e abandono das convenções sociais, acarretando um comportamento destrutivo ou uma enorme frustração com a qual a mente humana não é capaz de lidar (Sá 
et al., 2008; Steiner et al., 2013). Até mesmo porque para as pessoas as relações de apego são extremamente marcantes. Tuan (1980) denomina de topofilia a relação afetiva que alguém estabelece com o meio material que o cerca e topofobia a falta de afetividade ao mesmo lugar. Diante de um evento extremo, como uma inundação, é comum se observar as duas situações: pessoas que sofrem porque literalmente perderam o espaço físico onde, muitas vezes, durante toda a sua vida, criaram laços afetivos, e pessoas que diante de um abalo emocional tão marcante perdem a referência de afeto e o local até então desejado passa a ser aversivo.

Para Sá et al. (2008), pessoas que passam por eventos extremos sofrem significativos impactos em sua saúde mental, o que as torna atormentadas pelo medo e pela ansiedade de que o evento possa se repetir ou pela dor das perdas de entes queridos, bens afetivos e econômicos. Muitas apresentam reações emocionais muito intensas, mas compatíveis com o momento traumático vivenciado, enquanto que outras não apresentam estrutura emocional para lidar com tais situações e, consequentemente, adoecem de transtorno de estresse pós-traumático (TEPT), quando então os eventos extremos são considerados contextos desorganizadores ou disruptivos. Steiner et al. (2013) apontam estudos que demonstram que 75\% das pessoas expostas a uma situação traumática precisam ser avaliadas quanto à possibilidade de apresentarem distúrbios psíquicos com comorbidades associadas, tais como: depressão, ansiedade, fobia, abuso de drogas e álcool. As reações emocionais podem oscilar do pânico ao abatimento, afetando de forma diferente as pessoas, segundo suas características individuais (Steiner et al., 2013).

A necessidade de apoio emocional, de intervenção na dor e no sofrimento das vítimas, diretas e indiretas, é de fundamental importância para evitar sequelas que possam se generalizar, temporal e espacialmente, provocando transtornos psicológicos complexos. Até mesmo porque depende de cada pessoa o tempo em que ela pode manifestar os sintomas de TEPT, sendo que algumas apresentam logo após os eventos traumáticos e outras somente muitos anos depois (Sá et al., 2008). Nesse sentido, Reichert (2011) destaca a importância do papel que a psicologia tem desenvolvido, mediante a ação de profissionais capacitados e com o desenvolvimento de modelos de intervenção breves, por meio de técnicas de comunicação e modificação de comportamentos que visam oferecer ajuda em situações de impacto e perigo.

Além dos danos emocionais, também existem os riscos de doenças físicas, apontados pelos entrevistados. Freitas \& Ximenes (2012) destacam que as inundações afetam a distribuição de água potável e comumente tende a aparecer um considerável aumento na quantidade de mosquitos, moscas e ratos, assim como aumento da contaminação fecal por parasitas e helmintos e também contaminação da água, devido à propagação de contaminantes químicos.

A Tabela 6 descreve a percepção dos entrevistados em relação à maneira como a população reage após ter vivenciado os eventos de inundações.

TABELA 6 - Percepção dos atores sociais sobre como a população reage após os eventos de inundação em Itajaí (SC).

\begin{tabular}{|c|c|c|}
\hline & Respostas dos Atores de Instituições Governamentais & $\mathbf{N}$ \\
\hline A & Aumento da solidariedade, união. & 05 \\
\hline B & Mais preparada do que nas inundações anteriores & 02 \\
\hline $\mathrm{C}$ & $\begin{array}{l}\text { Ânimo, persistência, muita vontade de recuperar tudo o } \\
\text { que foi perdido. }\end{array}$ & 02 \\
\hline $\mathrm{D}$ & Depois da inundação foram construídos muitos prédios. & 01 \\
\hline $\mathrm{E}$ & $\begin{array}{l}\text { Pessoas preparadas para lutas, buscam união, cobram } \\
\text { mais dos governos. }\end{array}$ & 01 \\
\hline $\mathrm{F}$ & $\begin{array}{l}\text { Pessoas se unem com o coração, mas não têm a } \\
\text { consciência da prevenção. }\end{array}$ & 01 \\
\hline & $\begin{array}{c}\text { Respostas dos Atores de Instituições Não } \\
\text { Governamentais }\end{array}$ & $\mathbf{N}$ \\
\hline A & Pessoas buscam se organizar o mais rápido possível. & 05 \\
\hline B & Extrema solidariedade. & 03 \\
\hline $\mathrm{C}$ & $\begin{array}{l}\text { Com preocupação, insegurança de que vai alagar de } \\
\text { novo; dor, medo quando as pessoas ouvem a palavra } \\
\text { enchente. }\end{array}$ & 02 \\
\hline $\mathrm{D}$ & $\begin{array}{l}\text { Procuram assistencialismo e continuam morando no } \\
\text { mesmo lugar. }\end{array}$ & 02 \\
\hline $\mathrm{E}$ & Invasores cobram das autoridades o direito à moradia. & 01 \\
\hline $\mathrm{F}$ & $\begin{array}{l}\text { Revoltados, acham que o município tem que apresentar } \\
\text { uma solução, mas não têm solução. }\end{array}$ & 01 \\
\hline G & $\begin{array}{l}\text { Pessoas jogam os móveis estragados na calçada e } \\
\text { esperam que o município resolva. }\end{array}$ & 01 \\
\hline $\mathrm{H}$ & $\begin{array}{l}\text { No início as pessoas têm um período de preocupação, } \\
\text { mas depois esquecem e fogem do foco. }\end{array}$ & 01 \\
\hline
\end{tabular}

Observa-se que o grupo governamental demonstra-se mais positivo em comparação com o segundo grupo. 
Curiosamente, parece que o grupo não governamental possui a percepção de que a população, ao invés de reagir, demonstra-se mais dependente do governo, enquanto que para os atores governamentais a população apresenta boas condições de resiliência.

O termo resiliência tem sido interpretado como a habilidade de um sistema, comunidade ou sociedade exposta a riscos de resistir, absorver, acomodar-se e reconstruir-se diante dos efeitos de um desastre em tempo e modo adequados, incluindo a preservação e a restauração de suas estruturas e funções essenciais (PPRD, 2009). Para Jacinto (2012), a resiliência existe por oposição a um limiar crítico, sendo que a noção desse limiar crítico permite que sejam estabelecidas formas e ações para promover a distância entre o estado do sistema e o limite crítico, ou seja, para promover a resiliência. Para Buckerige (2008), a resiliência permite que um sistema permaneça estável mesmo quando sofre tensões razoáveis.

A resiliência também tem sido largamente usada pela biologia, referindo-se à adaptação de uma espécie, ou pela psicologia, enquanto capacidade de superação de um indivíduo. No entanto, quando se trata da capacidade de um ambiente ou sociedade de voltar às condições anteriores, após sofrer os impactos de um evento extremo, o termo passa a apresentar limitações, controvérsias ou ambiguidades, devido à complexidade que a questão apresenta, não podendo ser analisada de modo simplista ou reducionista, principalmente quando se trata de países não desenvolvidos, em que as condições de vidas anteriores aos eventos extremos já se demonstravam bastante precárias (Mendonça, 2011).

O marco de Sendai (UNISDR, 2012) conceitua resiliência numa concepção mais ampla, defendendo a importância de investimentos públicos e privados capazes de assegurar medidas estruturais e não estruturais que garantam a melhora da resiliência econômica, social, cultural e de saúde das pessoas, comunidades, países e do meio ambiente, visando prevenir e reduzir perdas, salvar vidas e garantir a recuperação e a reabilitação eficaz diante de um desastre. Contudo, este documento não menciona a resiliência como capacidade de superação no sentido de ir além da condição anterior.

Para Arciniega (2013), a resiliência pode ser dividida em três aspectos: como estabilidade, como recupe- ração e como transformação, sendo que nas percepções dos entrevistados em Itajaí predomina a resiliência como recuperação e como transformação, onde as pessoas saem mais fortalecidas ou transformadas positivamente, pois conseguem tirar algum proveito ou aprendem alguma lição com o fato ocorrido, embora essa hipótese necessite de maiores estudos.

Algumas respostas apontam uma resiliência comunitária, que refere-se à capacidade coletiva, de grupos de pessoas, de enfrentar as ameaças, conflitos, adversidades, que influenciam nos aspectos psicossociais de uma comunidade (Arciniega, 2013).

$\mathrm{Na}$ Tabela 7, é possível observar as percepções relativas à vulnerabilidade de Itajaí frente às inundações.

TABELA 7 - Percepção dos atores sociais sobre as maiores vulnerabilidades que a população apresenta frente às inundações em Itajaí (SC).

\begin{tabular}{llc}
\hline \multicolumn{2}{c}{ Respostas dos Atores de Instituições } & Novernamentais \\
\hline A & Falta de cuidados adequados com o meio ambiente. & 11 \\
B & Falta de investimento público. & 11 \\
C & Falta de educação ambiental. & 04 \\
D & Falta de atitude da população. & 04 \\
E & Cidade muito plana, sem lugar para onde ir, onde & \\
& colocar o carro na situação de inundação. & 01 \\
\hline & \multicolumn{1}{c}{ Respostas dos Atores de Instituições Não } & N \\
& \multicolumn{1}{c}{ Governamentais } & 12 \\
\hline A & Falta de investimento público. & 06 \\
B & Falta de atitude da população. & 04 \\
C & Falta de prevenção. & 01 \\
D & Saúde afetada. & \\
E & Saques em imóveis, quando as pessoas estão nos & 01 \\
& abrigos. & \\
F & Insegurança, compras excessivas em momentos de & 01 \\
& alerta. & 01 \\
G & Cidade muito concentrada, com alta taxa populacional. & 01 \\
H & Falta educação ambiental. \\
I & Não tem o que as pessoas possam fazer. & 01 \\
\hline
\end{tabular}

A Tabela 7 demonstra a predominância de respostas que indicam que a falta de maior investimento público e de cuidados com o meio ambiente tornam Itajaí mais vulnerável. Além disso, destacam a importância da educação ambiental, que, consequentemente, influi nas atitudes da população. Tais questões estão diretamente associadas entre si, considerando o conceito de educação 
ambiental como processo de desenvolvimento do senso crítico na busca de soluções para os problemas, portanto, tornando as pessoas proativas e, consequentemente, mais politizadas.

Infelizmente, a Tabela 7 demonstra que, decorridos mais de cinco anos desde a grande inundação de 2008, os atores sociais apontam que a cidade demonstra-se vulnerável diante de diferentes aspectos: falta de cuidados com o meio ambiente, falta de investimentos públicos e falta de atitudes da população, o que demonstra que, de maneira geral, este município avançou muito pouco na sua resiliência.

Importante verificar que parte dos entrevistados percebe como vulnerabilidade a situação geográfica (plana da cidade), intensificada pela concentração da ocupação, o que incorre em impermeabilidade do solo. Tucci (2008) aponta a impermeabilização dos solos como um dos problemas nas cidades, ao lado da falta de tratamento de esgoto, falta de redes de drenagem urbana, falta de canalização dos rios, falta de tratamento dos efluentes, entre outras questões.

De acordo com Bedin (2013), a cobertura vegetal de Itajaí foi intensamente alterada, especialmente na planície, ocupada pelos assentamentos urbanos e pelos sistemas agropastoris, predominando a rizicultura na área rural. As modificações ocorridas com a vegetação das margens dos rios e as características físico-químicas das águas têm causado, muitas vezes, a destruição ou a degradação do mosaico de biótopos e a biocenose, e a substituição da paisagem natural por outra artificial, ecologicamente empobrecida, leva à necessidade da ação e desenvolvimento de medidas para o controle de cheias e erosões.

Santos (2010) indica vários estudos que demonstram que um dos aspectos de maior vulnerabilidade de Itajaí diz respeito a sua localização geográfica, situada às margens e na foz do rio Itajaí-Açu, que recebe descarga de água e sedimentos ao longo da sua extensão. A porção do baixo curso do rio Itajaí-Açu constitui um estuário do tipo cunha salina, sendo caracterizado pela exportação de sedimento para a Plataforma Continental, onde o rio Itajaí-Açu é responsável por aproximadamente $90 \%$ do total do aporte fluvial para o estuário e os $10 \%$ restantes são atribuídos ao rio Itajaí-Mirim, que se encontra a aproximadamente $9 \mathrm{~km}$ da barra ou foz (Figura 1).
O fato de Itajaí estar localizada na foz do rio Itajaí e receber o aporte fluvial de toda bacia hidrográfica, associado a sua formação geológica, torna esta cidade um local propício a sofrer inundações periódicas dos leitos dos rios, o que historicamente é comprovado e acaba por gerar uma série de danos sociais e econômicos. Desde 1848, há registros de inundações no Vale de Itajaí, sendo, muitas vezes, muito próxima uma da outra, como nos anos de 1983 e 1984, ou até no mesmo ano, como em 1852 (Santos, 2010).

Nesse sentido, Martins (2010) alerta para a urgência de maior compreensão, principalmente por parte dos governantes, quanto à vulnerabilidade e necessidades de alternativas de adaptação em áreas urbanas, especialmente em regiões onde a pobreza e a taxa de crescimento são alarmantes. Nesse sentido, Melo \& Santos (2011) também apontam estudos que afirmam que o contingente populacional concentrado acaba por potencializar os impactos relacionados à ação de processos naturais, sejam de ordem geológica (terremotos, vulcões e tsunamis) ou climática (tempestades, furacões e tornados), uma vez que esses fenômenos acarretam um maior número de vitimados, principalmente em países de desenvolvimento desigual.

Santos (2007) demonstra que no Brasil os maiores desastres naturais relacionam-se a inundações, a escorregamentos e à erosão e que esses processos estão fortemente associados à degradação de áreas frágeis, potencializada pelo desmatamento e ocupações irregulares, sendo que é muito comum ver áreas naturais serem substituídas por áreas urbanas ou agricultura e entrecortadas por rodovias, dutos ou linhas de transmissão.

A recorrência das inundações pode acontecer por fatores naturais, que sempre existiram em toda a história da humanidade (Tucci, 2008), ou em função das alterações geoquímicas, dos ciclos de precipitações, do aquecimento global que o planeta vem sofrendo (IPCC, 2014). Contudo, o aspecto social e político, que diz respeito à forma como as cidades vêm sendo ocupadas e administradas, é um terceiro fator que deve ser considerado (Tucci, 2008).

A Tabela 8 apresenta as opiniões dos entrevistados a respeito dos instrumentos que estão atualmente à disposição do município de Itajaí com fins de amenizar ou prevenir danos, principalmente caso venha ocorrer nova inundação. 
TABELA 8 - Percepção dos atores sociais sobre os instrumentos a serviço do município que visam prevenir os danos decorrentes de inundações em Itajaí (SC).

\begin{tabular}{|c|c|c|}
\hline & Respostas dos Atores de Instituições Governamentais & $\mathbf{N}$ \\
\hline A & Aumento da estrutura da defesa civil. & 11 \\
\hline B & Planos de contingência, realização de simulados. & 02 \\
\hline $\mathrm{C}$ & $\begin{array}{l}\text { Macrodrenagem, limpeza e troca de tubulações, } \\
\text { dragagem constante. }\end{array}$ & 02 \\
\hline $\mathrm{D}$ & $\begin{array}{l}\text { Licenciamento ambiental com mais transparência em } \\
\text { relação à supressão da vegetação e à impermeabilidade } \\
\text { do solo. }\end{array}$ & 01 \\
\hline $\mathrm{E}$ & $\begin{array}{l}\text { Planejamento urbano adequado, estudo de impacto } \\
\text { de vizinhança, que embasa a liberação de licenças e } \\
\text { alvarás. }\end{array}$ & 01 \\
\hline $\mathrm{F}$ & $\begin{array}{l}\text { Projetos de construção de barragens junto ao governo } \\
\text { estadual. }\end{array}$ & 01 \\
\hline $\mathrm{J}$ & Reconstrução de ponte. & 01 \\
\hline \multirow[t]{2}{*}{ I } & Equipamentos, convênios com a EPAGRI. & 01 \\
\hline & $\begin{array}{c}\text { Respostas dos Atores de Instituições Não } \\
\text { Governamentais }\end{array}$ & $\mathbf{N}$ \\
\hline A & $\begin{array}{l}\text { Defesa civil, mapeamento de áreas de risco, com } \\
\text { equipamentos de telemetria e alertas via celular. }\end{array}$ & 10 \\
\hline B & $\begin{array}{l}\text { Sociedade civil organizada (clubes de serviços, } \\
\text { associações). }\end{array}$ & 01 \\
\hline $\mathrm{C}$ & Rede de informações ligadas a órgãos de previsões. & 01 \\
\hline $\mathrm{D}$ & Integração entre as defesas civis do estado. & 01 \\
\hline E & Retificação do rio Itajaí-Mirim. & 01 \\
\hline $\mathrm{F}$ & $\begin{array}{l}\text { Monitoramento através da Universidade do Vale do } \\
\text { Itajaí/UNIVALI. }\end{array}$ & 01 \\
\hline G & $\begin{array}{l}\text { Ação da defesa civil junto à Fundação Municipal de } \\
\text { Meio Ambiente de Itajaí/FAMAI. }\end{array}$ & 01 \\
\hline $\mathrm{H}$ & FAMAI com trabalhos de limpeza das ruas. & 01 \\
\hline I & Não há conhecimento. Só há aviso que o rio vai encher. & 01 \\
\hline
\end{tabular}

É possível verificar que a maioria das respostas dos sujeitos governamentais (11) destaca o incremento da Defesa Civil, principalmente depois de 2008, pois esta se estruturou em recursos humanos, escala de trabalhos, monitoramento dos rios e sistema de alerta à população, fazendo com que essa instituição tenha visibilidade e destaque junto aos sujeitos pesquisados.

Os entrevistados também apontam outras instituições envolvidas nas questões de inundações, além da Defesa Civil, como a EPAGRI (Empresa de Pesquisa Agropecuária e Extensão Rural de Santa Catarina), a UNIVALI (Universidade do Vale do Itajaí) e a FAMAI (Fundação Municipal do Meio Ambiente de Itajaí), além da sociedade civil organizada. Isto sugere que, para o enfrentamento e a minimização das inundações em Itajaí, um consórcio de Instituições pode ser mais efetivo.

No continente europeu, devido à recorrência de eventos de inundações nas últimas décadas, os governos formaram a chamada Comissão Europeia, voltada a planejar e desenvolver ações de avaliação de risco e enfrentamento das inundações. Especificamente na França, a partir de 2002, com a recorrência de eventos de inundações, desenvolveu-se o chamado PAPI (Programa de Ações e Prevenções contra Inundações). Nesse programa cada ação é descrita, justificada quanto a sua prioridade, aos tipos de financiamento, à origem do recurso, às formas de execução e monitoramento mediante indicadores de acompanhamento (PAPI, 2014). Também pode ser destacada a China, onde desde 2000 , devido à ocorrência cada vez maior de inundações, buscou-se adotar medidas em 1.836 municípios daquele país, incluindo a definição das áreas de risco, determinação de precipitação crítica capaz de indicar a ocorrência de inundações, adaptação de equipamentos de monitoramento, adoção de equipamento de alerta aos municípios, estabelecimento de hierarquia de responsabilidades (Sun et al., 2012).

De acordo com Tucci (2008), o Brasil evoluiu nos últimos anos, principalmente quanto à gestão de recursos hídricos, considerando o Plano Nacional de Recursos Hídricos e a Agência Nacional das Águas, mas ainda faltam planos de ações voltados a atingir metas. Martins \& Ferreira (2011) também destacam a importância da adaptação, como um conjunto de ações focalizadas a um determinado sistema vulnerável (podendo ser um setor da economia, uma atividade agrícola, um bairro, uma cidade, uma região), como forma de atenuar os impactos e reduzir danos causados por estímulos climáticos correntes ou futuros.

A Tabela 9 apresenta a visão dos entrevistados a respeito das ações educacionais que o município vem desenvolvendo.

Observa-se que enquanto a maioria (09) dos entrevistados governamentais afirma existir algum programa educacional em Itajaí voltado à prevenção das inundações, a metade dos entrevistados de instituições não governamentais demonstra não conhecer nenhuma ação dessa natureza, expressando a necessidade do município em dar mais visibilidade a tais ações. 
TABELA 9 - Percepção dos atores sociais sobre programas ou ações educacionais que tenham por finalidade prevenir as ameaças das inundações em Itajaí (SC).

\begin{tabular}{llc}
\hline \multicolumn{2}{c}{$\begin{array}{c}\text { Respostas dos Atores de Instituições } \\
\text { Governamentais }\end{array}$} & N \\
\hline A & Há programas e ações. & 09 \\
B & Há campanhas, mas não existem programas. & 01 \\
C & Desconhece. & 01 \\
D & Não há programas e ações. & 01 \\
\hline \multicolumn{2}{c}{ Respostas dos Atores de Instituições Não } \\
\multicolumn{2}{c}{ Governamentais } \\
\hline A & Há programas e ações. & 06 \\
B & Desconhece. & 05 \\
C & Não há serviço de orientação. & 01 \\
\hline
\end{tabular}

Quanto à educação ambiental, pode-se afirmar que esta representa uma importante ferramenta capaz de auxiliar as pessoas, seja em qual contexto for, a buscar mudanças de valor, comportamentos, sentimentos e atitudes, promovendo, assim, a emancipação humana e formando pessoas com capacidade crítica de interpretar a realidade onde vivem (Oliveira \& Rutkowski, 2008). De acordo como o indivíduo percebe o mundo que o cerca, ele vai formando juízos de valores e assim estabelecendo suas atitudes, mas estas podem ser influenciadas, modificadas, extintas ou reforçadas, de acordo com as respostas que o meio social oferece a essa pessoa. Segundo Carvalho et al. (2009), entre os muitos caminhos que têm sido apontados como possibilidades de minimização das alterações ambientais provocadas pelo homem, destaca-se em evidência a importância da educação que, vista como prática social, poderá gerar movimentos de transformação e de alteração dos níveis alarmantes de degradação da qualidade de vida e do ambiente a que está sujeita grande parte da população do planeta.

As ações de educação ambiental são necessárias para fortalecer os indivíduos nas suas tomadas de decisões e até mesmo qualificar a percepção que devem possuir diante do lugar em que vivem, pois pode-se afirmar que, além das limitações das políticas públicas para lidar com as consequências das alterações climáticas, também existem as limitações na esfera individual, onde uma é fruto da outra e se retroalimentam.

Considerando que os atores governamentais são representantes de órgãos públicos municipais, os mesmos deveriam naturalmente estar envolvidos com as questões de prevenção e minimização dos impactos das inundações. Mas, no presente estudo, observou-se também que muitas instituições privadas também se envolveram em ações humanitárias, principalmente no momento das inundações. Mas, infelizmente, nos períodos pós-inundações, percebe-se que poucas ações são desenvolvidas.

\section{Considerações finais}

Os eventos extremos como respostas às alterações climáticas, aliados ao fato de que Itajaí situa-se na planície que compreende a foz do rio Itajaí-Açu, recebendo o aporte de energia e de matéria de toda bacia hidrográfica, tornam a região vulnerável às inundações. Na presente pesquisa, foi possível constatar que os atores sociais amostrados percebem como as variações climáticas globais estão atuando no município, por meio de alterações na temperatura, estações do ano mal definidas e a presença mais constante de inundações. De fato, além do exposto pela mídia internacional, vivenciar as inundações de 2008 e 2011 acrescenta o fator afetivo ao fator cognitivo nas percepções dos envolvidos, mesmo que não afetados diretamente.

Nesse sentido, já que as variações climáticas representam uma realidade presente, os atores percebem a importância e reconhecem a estruturação da Defesa Civil em Itajaí, destacando ainda a necessidade de obras de infraestrutura. Por outro lado, denotam certa ausência de políticas públicas e a necessidade de fiscalização e de educação ambiental.

Os danos e as perdas materiais ampliam o sentimento de impotência, mas contribuem para tornar as pessoas afetadas pelas inundações indivíduos mais resilientes, pois mobilizam a população a ir em busca do que perdeu. Mas, infelizmente, a população de Itajaí ainda parece socialmente pouco organizada, uma vez que as ações coletivas só se mantêm durante os eventos extremos, neste caso de Itajaí, chuvas de grande intensidade associadas à subida de maré por se tratar de região de planície de inundação.

Programas ou ações educacionais são extremamente importantes, pois podem minimizar os problemas ambientais, especialmente aqueles associados ao assoreamento do rio e à impermeabilização dos solos. 
Esta pesquisa buscou informações científicas que possibilitam ao município de Itajaí investir em ações concretas que o tornem mais adaptado e resiliente frente aos cenários de variações climáticas e também diante de um histórico de reincidências de episódios de inundações.

\section{Referências}

Arciniega, J. D. U. A. La perspectiva comunitaria de la resiliencia. Psicología Política, 47, 7-18, 2013. Disponível em: $<$ http://www.uv.es/garzon/psicologia\%20politica/N47-1.pdf>.

Bedin, F. A. Ecologia da Paisagem como subsídio para implantação do Parque Municipal da Ressacada - Itajai - Santa Catarina - Brasil. Itajaí, Dissertação (Mestrado em Ciência e Tecnologia Ambiental) - UNIVALI, 2013.

Bitsch, V. Qualitative Research: A Grounded Theory Example and Evaluation Criteria. Journal of Agribusiness, 23(1), 7591, 2005. Disponível em: <http://ageconsearch.umn.edu/ bitstream/59612/2/S05-05.pdf $>$.

Brasil. TCU - Tribunal de Contas da União. Referencial básico de governança: Aplicável a órgãos e entidades da administração pública. Brasília, 2013. Disponível em: <http://portal3. tcu.gov.br/portal/page/portal/TCU/comunidades/governanca/ Banco\%20de\%20Imagens/Gov-Ref-v142.pdf $>$. Acesso em: jun. 2015.

Buckerige, M. S. (Org.). Biologia \& mudanças climáticas no Brasil. São Carlos: RiMa Editora, 2008.

Carvalho, L. M.; Tomazello, M. G. C.; Oliveira, H. T. Pesquisa em educação ambiental: panorama da produção brasileira e alguns de seus dilemas. Cadernos CEDES, 29(77), 13-27, 2009.

Casagrande, A.; Silva Jr., P.; Mendonça, F. Mudanças climáticas e aquecimento global: controvérsias, incertezas e a divulgação científica. Revista Brasileira de Climatologia, 8, 30-44, 2011.

Cordero, A.; Medeiros, P. A.; Teran, A. L. Medidas de controle de cheias e erosões. CEOPS - Centro de Operações de Sistemas de Alertas. Universidade Regional de Blumenau, 1999. Disponível em: <http://ceops.furb.br/index.php/publicacoes/ documentos/search_result $>$. Acesso em: set. e 2015.

Figueiredo, M. Z. A.; Chiari, B. M.; Goulart, B. N. G. Discurso do Sujeito Coletivo: uma breve introdução à ferramenta de pesquisa qualiquantitativa. Distúrbio Comunicação, 25(1),
Espera-se que estudos como este possam contribuir com a efetivação de propostas de se construir cidades mais resilientes e para a melhor efetivação de medidas de redução de riscos de desastres.

129-136, 2013. Disponível em: <http://revistas.pucsp.br/index. php/dic/article/viewFile/14931/11139>.

Fogaça, T. K.; Limberger, L. Percepção ambiental e climática: estudo de caso em colégios públicos do meio urbano e rural de Toledo-PR. Revista do Departamento de Geografia - USP, 28, 134-156, 2014. Disponível em: <file:///C:/Users/ Ad\%C3\%A3o/Downloads/90009-129174-1-PB\%20(3).pdf .

Fontanella, B. J. B.; Ricas J.; Turato, E. R. Amostragem por saturação em pesquisas qualitativas em saúde: contribuições teóricas. Cadernos de Saúde Pública, 24(1), 17-27, 2008.

Freitas, C. M. de; Ximenes, E. F. Enchentes e saúde pública: uma questão na literatura científica recente das causas, consequências e respostas para prevenção e mitigação. Ciência \& Saúde Coletiva, 17(6), 1601-1616, 2012.

Gomes, E. R. B.; Cavalcante, A. C. S. Desastres naturais: perdas e reações psicológicas de vítimas de enchente em Teresina-PI. Psicologia \& Sociedade, 24(3), 720-728, 2012. Disponível em: $<$ http://www.scielo.br/pdf/psoc/v24n3/25.pdf $>$.

IBGE - Instituto Brasileiro de Geografia e Estatística. Relatório de Estação Geodésica, 2015. Disponível em: <http://www.bdg. ibge.gov.br/bdg/pdf/relatorio.asp?L1=8114583>.

IPCC - Intergovernmental Panel on Climate Change. Impacts, Adaptation, and Vulnerability, Part A: Global and Sectoral Aspect. Contribution of Working Group II to the Fifth Assessment Report of the Intergovernmental Panel on Climate Change. C. B. V.R. Barros, D.J. Dokken, K. J. Mach, M. D. Mastrandrea, T. E. Bilir, M. Chatterjee, K. L. Ebi, Y. O. Estrada, R. C. Genova, B. Girma, E. S. Kissel, A. N. Levy, S. MacCracken, P. R. Mastrandrea, and L. L. White (Eds.). Cambridge: Cambridge University Press, 2014.

Jacinto, R. Resiliência a eventos de seca e cheia no contexto dos instrumentos de planeamento (ordenamento e emergência). Cadernos Curso de Doutoramento em Geografia FLUP, 2012. Disponível em: $<$ http://ler.letras.up.pt/uploads/ficheiros/9961. pdf>. 
Jorge, F. V. Fachada Atlântica Sul do Brasil: dinâmica e tendências climáticas regionais no contexto das mudanças globais. Curitiba, Dissertação (Mestrado em Geografia) -UFPR, 2009.

Kobiyama, M.; Mendonça, M.; Moreno, D. A.; Marcelino, I. P. V. D. de O.; Marcelino, V. E.; Gonçalves, E. F.; Brazetti, L. L. P.; Goerl, R. F.; Molleri, G. S. F.; Rudorff, F. de M (Org.). Prevenção de desastres naturais: conceitos básicos. Curitiba: Ed. OrganicTrading, 2006.

Kuhnen, A. Meio ambiente e vulnerabilidade: a percepção ambiental de risco e o comportamento humano. Geografia, 18(2), 2009. Disponível em: <http://www.ceped.ufsc.br/wp-content/ uploads/2014/07/meio_ambiente_e_vulnerabilidade_a_percepcao_ambiental.pdf $>$.

Lefevre, F.; Lefevre, A. M. C. Discurso do Sujeito Coletivo: um novo enfoque em pesquisa qualitativa (desdobramentos). Caxias do Sul: EDUCS, 2003.

Lefevre, F.; Lefevre, A. M. C. O sujeito coletivo que fala. Interface, 10(20), 517-524, 2006. Disponível em: <http://www. scielosp.org/pdf/icse/v10n20/17.pdf>.

Mendonça, F. Riscos, Vulnerabilidades e Resiliência Socioambientais Urbanas: inovações na análise geográfica. Revista da ANPEGE, 7, 111-118, 2011.

Marengo, J. A. Água e mudanças climáticas. Estudos Avançados, 22(63), 83-96, 2008.

Martins, R. A. Governança climática nas cidades: reduzindo vulnerabilidades e aumentando resiliência. Revista Geográfica Acadêmica, 4(2), 2010.

Martins, R. A.; Ferreira, L. da C. Uma revisão crítica sobre cidades e mudança climática: vinho velho em garrafa nova ou um novo paradigma de ação para a governança local? Revista de Administração Pública, 45(3), 611-41, 2011.

Melo, C. A.; Santos, F. A. dos. As contribuições da psicologia nas emergências e desastres. Psicólogo Informação, 15, 2011. Disponível em: <https://www.metodista.br/revistas/revistas-ims/index.php/PINFOR/article/viewFile/3177/3045>.

Mezoni, W. J. Pesquisas contra desastres. Abstract. Revista da Pró-Reitoria da Universidade do Vale do Itajai, 14, 2011.

Oliveira, E. T.; Rutkowski, E. W. Mudanças climáticas e mudanças socioambientais globais: reflexões sobre alternativas de futuro. Brasília: UNESCO, IBECC, 2008.

PAPI - Programme d'Actions de Prévention des Inondations de La Seineet de La Marne Franciliennes. EPTB Seine Grands Lacs, 2014. Disponível em: <http:/www.seinegrandslacs.fr/ programme-d-actions-de-prevention-des-inondations-papi>. Acesso em: jan. 2015.

Polette, M.; Marenzi, R. C.; Santos C. F. Atlas Socioambiental de Itajaí. Itajaí: Editora da UNIVALI, 2012.

PPRD - Plano Integrado de Prevenção e Mitigação de Desastres Naturais na Bacia Hidrográfica do Rio Itajaí. Florianópolis, 2009. Disponível em: <http://189.73.116.32/xmlui/bitstream/ handle/123456789/228/Plano_Integrado_PPRD-Itajai. pdf? sequence $=2>$. Acesso em: jan. 2014.

Rejaneda, R. G. L.; Silva, T. N.; Maffini, G. C. O papel das partes interessadas (stakeholders) e a participação na gestão de recursos hídricos: um estudo no comitê Santa Maria. Revista de Administração FACES Journal, 10(3), 168-188, 2011.

Reichert, T. R. Psicologia de emergências e desastres na América Latina: promoção de direitos e construção de estratégias de atuação. Brasília: Conselho Federal de Psicologia, 2011.

Righi, E.; Robaina, S. E. L. Enchentes do Rio Uruguai no Rio Grande do Sul entre 1980 e 2005: uma análise geográfica. Sociedade \& Natureza, 22(1), 35-54, 2010. Disponível em: $<$ http://www.seer.ufu.br/index.php/sociedadenatureza/article/ viewFile/9973/5918>.

Roseguini, W. F. F.; Mendonça, F. A. Natural Hazards e urbanização: considerações sobre risco e vulnerabilidade socioambiental em Santa Catarina - Brasil. In:Anais do VI Seminário Latino-Americano de Geografia Física e II Seminário Ibero- Americano de Geografia Física Universidade de Coimbra, maio de 2010. Disponível em: <http://www.uc.pt/fluc/cegot/ VISLAGF/actas/tema4/wilson>.

Sá, S. D.; Guevara W. B. S.; Esteves, P. M. Intervenção em crise. Revista Brasileira de Terapias Cognitivas, 4(1), 2008.

Santos, C. F. A enchente em Itajaí (SC): relatos, percepções e memórias. Florianópolis, Dissertação (Mestrado Profissional em Planejamento Territorial e Desenvolvimento Socioambiental) - UFSC, 2010.

Santos, C. F.; Tornquist, S.; Marimon, C. P. M. Indústria das enchentes: impasses e desafios dos desastres socioambientais no Vale do Itajaí. Geosul, 29(57), 197-216, 2014.

Santos, R. F. (Org.). Vulnerabilidade ambiental. Brasília: MMA, 2007.

Sartori, M. G. B.; Wollmann, C. A. A percepção ambiental e climática da população de São Sebastião do Caí como forma de previsão de enchentes na Bacia Hidrográfica do Rio Caí - Rio Grande do Sul. Revista Brasileira de Climatologia, 6, 2010. 
Silveira, A. L. L. Drenagem urbana: aspectos de gestão. Instituto de Pesquisas Hidráulicas. Universidade Federal do Rio Grande do Sul, 2002. Disponível em: <ftp://ftp.cefetes.br/ cursos/transportes/Zorzal/Drenagem\%20Urbana/Apostila\%20 de $\% 20$ drenagem $\% 20$ urbana $\% 20$ do $\% 20$ prof $\% 20$ Silveira.pdf $>$.

Steiner, O.; Helena, E. T. S. Gios, T. S.; Rowe, A.; Takeshita, B. T. Prevalência de suicídio relacionada à enchente de novembro de 2008 no Estado de Santa Catarina. Arquivo Catarinense de Medicina, 42(3), 9-14, 2013.

Sun, D.; Zhang, D.; Cheng, X. Framework of National NonStructural Measures for Flash Flood Disaster Prevention in China. Water, 4, 272-282, 2012. doi: 10.3390/w4010272.

Tuan, Yi-Fu. Topofilia: um estudo da percepção, atitudes e valores do meio ambiente. São Paulo: Difel, 1980.

Tucci, C. E. M. Gestão de águas pluviais urbanas. Ministério das Cidades - Global Water Partnership - World Bank: Unesco.
2005. Disponível em: <file://C:/Users/Ad\%C3\%A3o/Downloads/gestaodeaguaspluviais.pdf $>$. Acesso em: jan. 2014.

Tucci, C. E. M. Águas urbanas. Estudos Avançados, 22(63), 97-112, 2008.

UNISDR - The United Nations Office for Disaster Risk Reduction. Como construir cidades mais resilientes: um guia para gestores públicos locais. Suíça: Escritório das Nações Unidas para Redução de Riscos de Desastres, 2012. Disponível em: $<$ http://www.unisdr.org/files/26462_guiagestorespublicosweb. pdf $>$. Acesso em: ago. 2015.

UNISDR - The United Nations Office for Disaster Risk Reduction. Sendai Framework for Disaster Risk Reduction 2015-2030,2015. Disponível em: <http://www.preventionweb. net/files/43291_sendaiframeworkfordrren.pdf $>$. Acesso em: ago. 2015. 


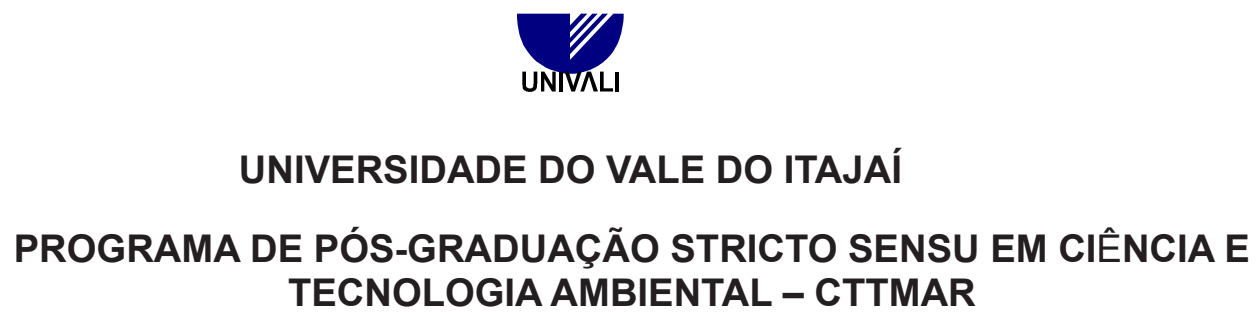

\section{PERCEPÇÃO, RESILIÊNCIA E ADAPTAÇÃO DE ATORES SOCIAIS DE ITAJAÍ - SC FRENTE ÀS MUDANÇAS CLIMÁTICAS, COM FOCO NAS INUNDAÇÕES.}

Número do questionário:

Data da entrevista:

Nome:

Idade:

Estado Civil:

$\mathrm{N}^{\mathrm{o}}$ de filhos:

Local de trabalho:

Cargo/Função:

Escolaridade:

Especialização:

Há quanto tempo está nessa Instituição:

Residente em Itajaí: ( ) Não. （ ) Sim - Há quanto tempo:

Endereço:

\section{0 -Mudanças climáticas (Impacto e Respostas):}

1.1 - Na sua percepção, você considera que as mudanças climáticas globais estão atuando no município de Itajaí? Sim( ); Não ( ) - Justifique:

1.2 - Quais as iniciativas que o município de Itajaí vem adotando para reduzir a vulnerabilidade frente às mudanças climáticas?

1.3 - Quais as ações que podem ser desenvolvidas no município de Itajaí para redução dos impactos antrópicos sobre o clima?

2.0 - Percepção Quanto as Inundações no município de Itajaí (Impacto):

2.1 - Quais os principais danos sofridos pela população do município de Itajaí frente às inundações?

2.2 - Quais são as maiores vulnerabilidade que a população de Itajaí apresenta frente às inundações?

3.0 - Capacidade de Resiliência e de Adaptação (Resposta)

3.1 - Como a população de Itajaí reage após os eventos de inundação?

3.2 - Quais são as políticas públicas que você considera que o município de Itajaí vem adotando frente a possibilidade de novas inundações?

3.3 - Quais os dispositivos/instrumentos que atualmente estão a serviço do município de Itajaí que visam prevenir os danos decorrentes de inundações?

3.4 - Cite, na sua opinião, três instituições que você considera mais motivadas para enfrentar os problemas das inundações em Itajaí?

3.5 - Existem no município de Itajaí programas ou ações educacionais que tenham por finalidade prevenir as ameaças das inundações? Sim ( ); Não ( ) - Quais:

428 MORAES, A. de S.; MARENZI, R. C.; LONGARETE, C. Percepção de atores sociais de Itajaí (SC) a respeito das variações climáticas... 